\title{
Knowledge, attitudes and practices (KAP) relating to avian influenza in urban and rural areas of China
}

\author{
Nijuan Xiang ${ }^{1 \dagger}$, Ying Shi ${ }^{1,2 \dagger}$, Jiabing $\mathrm{Wu}^{3 \dagger}$, Shunxiang Zhang ${ }^{4 \dagger}$, Min Ye ${ }^{1}$, Zhibin Peng ${ }^{1}$, Lei Zhou ${ }^{1}$, Hang Zhou', \\ Qiaohong Liao', Yang Huai', Leilei Li ${ }^{5}$, Zhangda Yu ${ }^{6}$, Xiaowen Cheng ${ }^{4}$, Weike Su${ }^{7}$, Xiaomin $\mathrm{Wu}^{4}$, Hanwu Ma ${ }^{4}$, \\ Jianhua Lu', Jeffrey McFarland ${ }^{8}$, Hongjie $Y_{u^{1 *}}$
}

\begin{abstract}
Background: Studies have revealed that visiting poultry markets and direct contact with sick or dead poultry are significant risk factors for $\mathrm{H} 5 \mathrm{~N} 1$ infection, the practices of which could possibly be influenced by people's knowledge, attitudes and practices (KAPs) associated with avian influenza (Al). To determine the KAPs associated with Al among the Chinese general population, a cross-sectional survey was conducted in China.

Methods: We used standardized, structured questionnaires distributed in both an urban area (Shenzhen, Guangdong Province; $n=1,826$ ) and a rural area (Xiuning, Anhui Province; $n=2,572$ ) using the probability proportional to size (PPS) sampling technique.
\end{abstract}

Results: Approximately three-quarters of participants in both groups requested more information about Al. The preferred source of information for both groups was television. Almost three-quarters of all participants were aware of Al as an infectious disease; the urban group was more aware that it could be transmitted through poultry, that it could be prevented, and was more familiar with the relationship between Al and human infection. The villagers in Xiuning were more concerned than Shenzhen residents about human Al viral infection. Regarding preventative measures, a higher percentage of the urban group used soap for hand washing whereas the rural group preferred water only. Almost half of the participants in both groups had continued to eat poultry after being informed about the disease.

Conclusions: Our study shows a high degree of awareness of human Al in both urban and rural populations, and could provide scientific support to assist the Chinese government in developing strategies and health-education campaigns to prevent $\mathrm{Al}$ infection among the general population.

\section{Background}

As of July 1 2009, 436 confirmed human H5N1 avian influenza (AI) cases, resulting in 262 deaths (case fatality rate, 60.1\%), have been reported since November 2003, most of them in southeast Asia [1]. There is general agreement on the potential spread to humans with devastating consequences [2]. Case-control studies during the 1997 outbreak in the Hong Kong Special Administrative Region (SAR) of China [3], Thailand [4],

\footnotetext{
*Correspondence: yuhj@chinacdc.cn

† Contributed equally

'Office for Disease Control and Emergency Response, Chinese Center for Disease Control and Prevention, Beijing, China
}

Vietnam [5] and China [6] during 2004-2005 revealed the visiting of poultry markets and direct contact with sick or dead poultry to be significant H5N1 risk factors.

In mainland China, 37 confirmed $\mathrm{H} 5 \mathrm{~N} 1$ cases have been reported since October 2005 [7]. The Chinese H5N1 cases comprised two different groups regarding patterns of exposure to poultry: $71.4 \%(10 / 14)$ of urban patients had visited wet poultry markets (live or freshly slaughtered poultry) before onset of the illness, whilst $81.8 \%(18 / 22)$ of rural patients had previously been exposed to backyard poultry and to sick or dead poultry $[6,8]$.

To date, there are limited data on the knowledge, attitudes and practices (KAPs) associated with AI in the

\section{Biomed Central}


general population $[9,10]$. We conducted a two-stage, household-based cluster survey of KAPs regarding AI in an urban area (city of Shenzhen), where poultry markets are common, and in a rural area (Xiuning County), where backyard poultry is common. Focal points of the survey were: types of information commonly held, awareness of AI, emotional reactions to human AI, and practices associated with its prevention.

\section{Methods}

\section{Study Sites}

The study was performed in Shenzhen city; a typical large urban population located in Guangdong Province, southeast China, just across the border from Hong Kong SAR, and in Xiuning County (Anhui Province in the middle of China); a typical rural area with a population of 240,000 .

\section{Sample Size}

A two-stage probability proportional to size (PPS) sampling method was used. In stage one, we selected 30 primary sample units (PSUs) from the 639 communities in Shenzhen and 30 PSUs from the 259 villages in Xiuning, ranked by population using SAS (Survey Select Procedure with PPS-systematic sample method, version 9.0; SAS Inc, Cary, NC, USA). In stage two, 20 households in each community of Shenzhen and 30 households in each village in Xiuning were randomly selected. A sample size of 1,750 participants in Shenzhen was calculated to achieve a point estimation with an $\alpha$-error of 0.05 , based on an estimated prevalence (about 20\%) of chickens purchased live in Hong Kong SAR [9]. For Xiuning, it was estimated that about $50 \%$ of households would raise backyard poultry, requiring a maximum sample of 2,700. In both cases, sample sizes took into account the different sampling methods and assumed a response rate of $80 \%$.

\section{Survey Methodologies}

Trained investigators from the Chinese Center for Disease Control and Prevention (China CDC, Beijing) and local CDCs described the purpose of the study to eligible participants or their proxies and obtained oral informed consent before the enrollment. In each household, every family member who met the inclusion criteria was administered a standardized, structured questionnaire (see Additional file 1; and Additional file 2 ) in the local language to assess KAPs of AI. The inclusion criteria were: proper communication skills, age $\geq 15$ years, and residence in the specific investigational area for $\geq 3$ months.

Most questions were closed-ended: participants were allowed to choose from a pre-existing set of answers (Yes/No/Unclear). Most variables derived from these questions were categorical, with the exception of age.
The level of knowledge of AI was assessed according to awareness of the issue, sources of information and demand for more information. We also asked both groups whether or not AI is an infectious condition (3 points), to describe its mode of transmission (2 points), whether or not it can be prevented (1 point), and to estimate the level of recovery after treatment (1 point). Only the urban group was asked whether infection is associated with hygiene in wet poultry markets (1 point), and only the rural group was asked about the relationship between AI and 'fowl plague' (Newcastle disease) (1 point). In order to be considered knowledgeable, a participant had to attain a score of five points or more out of eight, according to a Likert-type scale $[11,14]$.

Concerns related to AI were assessed via two questions regarding concerns about family/friends and fear of visiting public places due to the risk of catching the virus. To each question a maximum of 3 points was assigned if the answer was 'yes'; 2 points were assigned to 'not sure'; 1 point was assigned to 'unknown'; and 0 points for 'no'. A person who scored 5 or 6 points was defined as concerned about AI.

Practices associated with preventing human AI were also assessed, with questions about hand washing and eating poultry after being informed about AI. Urban residents were asked about direct contact with live poultry when purchasing in a wet poultry market, including direct contact with cages of live poultry and subsequent inoculation of mucous membranes after touching poultry cages. Rural participants, more likely to have contact with backyard poultry, were questioned on their exposure to sick or dead poultry.

\section{Statistical Analysis}

Data from the questionnaires were entered in duplicate and verified using EpiData software (Odense, Denmark; available at http://www.epidata.dk/). Data were analyzed with SPSS (version 13.0; SPSS Inc., Chicago, IL, USA). Median and range values were calculated for continuous variables, and were compared between urban and rural groups using the Wilcoxon rank-sum test. For categorical variables, frequencies for urban and rural groups were compared using the chi-square test. A backward variable selection method was used to select variables for multivariate analysis by univariate analysis. The multiple linear regression model was used to analyze possible influencing factors associated with participants' AI knowledge and attitudes.

\section{Study Approval}

The study protocol was approved by the Institutional Review Board of the China CDC and was carried out in compliance with the Helsinki Declaration. The 
requirement for signed, informed consent was waived because no sensitive individual information or clinical specimens were collected from participants. Verbal informed consent was obtained from all participants.

\section{Results}

4,414 (98\%) of the 4,504 eligible participants agreed to participate in the study and completed the questionnaire. Fifteen participants in Shenzhen and one in Xiuning were excluded from the analysis due to incomplete responses. Residents in the Shenzhen group were significantly younger than those in Xiuning $(p<0.001)$, with a median age of 32 years and 46 years, respectively. The level of education (high school or above) was much higher among the urban residents compared to the rural villagers: $760(42 \%)$ vs. $199(8 \%)$, respectively ( $p<$ 0.001). A similar difference was observed in occupation levels: 244 (13\%) of participants were homemakers in Shenzhen vs. $39(2 \%)$ in Xiuning $(p<0.001)$.

The most common source of information about human AI was television, with $94 \%$ of urban residents and $92 \%$ of rural residents $(p=0.04)$ identifying television as the main source of information on AI. Urban Shenzhen residents were more likely than rural Xining residents to be informed through newspapers ( $45 \%$ vs. $7 \%, p<0.001)$ or the internet $(21 \%$ vs. $2 \%, p<0.001)$. More residents in the Xiuning group obtained information through health professionals $(26 \%$ vs. $7 \%, p<$ 0.001 ) and family/friends ( $55 \%$ vs. $29 \%, p<0.001$ ).

A significant percentage of participants in both groups requested more information (62\% for the Shenzhen group and $76 \%$ for the Xiuning group, $p<0.001$ ). However, approximately a quarter of the population in both groups did not care about this problem (Shenzhen $28 \%$ vs. Xiuning $22 \%, p<0.001$ ). Official announcements of a poultry outbreak were less frequently demanded, especially by the Xiuning group $(p<0.001)$. Television was the preferred source of further information in $92 \%$ of the Shenzhen group and $95 \%$ of the Xiuning group $(p<0.001)$ (Table 1$)$.

Almost three-of all participants were aware AI is an infectious disease that can be prevented; $40 \%$ of participants in the Shenzhen group vs. $31 \%$ in the Xiuning group $(p<0.001)$ were aware the infection could be transmitted from poultry; however, only $4 \%$ of urban and $6 \%$ of rural participants were aware that humans could fail to recover fully with treatment. Overall, a greater proportion of urban participants were considered to be knowledgeable about human infection with AI (Shenzhen group 69\% vs. Xiuning group 56\%; $p<0.001$ ) (Table 2). A comparison of knowledge scores associated with AI for all interviewed respondents in Shenzhen city and Xiuning county found the same result; that urban residents were more knowledgeable about AI than the rural villagers $(p<0.001)$ (Table 3$)$.
Table 1 Sources of Al information among urban residents in Shenzhen and rural villagers in Xiuning, China

\begin{tabular}{|c|c|c|c|}
\hline Variable & $\begin{array}{l}\text { Residents in } \\
\text { Shenzhen }(n= \\
1,826) \text { No. }(\%)\end{array}$ & $\begin{array}{l}\text { Villagers in } \\
\text { Xiuning }(\mathrm{n}= \\
2,572) \text { No. }(\%)\end{array}$ & $P$ value* \\
\hline Had heard of Al & $1,652(90)$ & $2,263(88)$ & 0.009 \\
\hline \multicolumn{4}{|l|}{ Information source ${ }^{ \pm}$} \\
\hline Television & $1,518(92)$ & $2,118(94)$ & 0.041 \\
\hline Newspapers & $740(45)$ & $158(7)$ & $<0.001$ \\
\hline Family/friends & $477(29)$ & $1,235(55)$ & $<0.001$ \\
\hline Internet & $339(21)$ & $47(2)$ & $<0.001$ \\
\hline Radio broadcast & $194(12)$ & $149(7)$ & $<0.001$ \\
\hline Health facility & $114(7)$ & $579(26)$ & $<0.001$ \\
\hline \multicolumn{4}{|c|}{ Requested more information on $\mathrm{Al}$} \\
\hline Yes & $1,135(62)$ & $1,968(76)$ & \\
\hline No & $182(10)$ & $47(2)$ & $<0.001$ \\
\hline Did not care & $509(28)$ & $557(22)$ & \\
\hline \multicolumn{4}{|c|}{ Type of information requested on $\mathrm{Al}^{ \pm}$} \\
\hline Prevention & $1,039(92)$ & $1,876(95)$ & $<0.001$ \\
\hline $\begin{array}{l}\text { Basic } \\
\text { knowledge }\end{array}$ & $741(65)$ & $1,011(51)$ & $<0.001$ \\
\hline Therapy & $629(55)$ & $851(43)$ & $<0.001$ \\
\hline $\begin{array}{l}\text { Official } \\
\text { announcement } \\
\text { of poultry } \\
\text { outbreak }\end{array}$ & $476(42)$ & $181(9)$ & $<0.001$ \\
\hline \multicolumn{4}{|c|}{ Requested more information on $\mathrm{Al}$ through $^{ \pm}$} \\
\hline Television* & $1,044(92)$ & $1,922(98)$ & $<0.001$ \\
\hline Newspapers & $546(48)$ & $228(12)$ & $<0.001$ \\
\hline Internet & $276(24)$ & $68(3)$ & $<0.001$ \\
\hline $\begin{array}{l}\text { Healthcare } \\
\text { workers }\end{array}$ & $154(14)$ & $798(41)$ & $<0.001$ \\
\hline Radio broadcast & $147(13)$ & $203(10)$ & 0.025 \\
\hline Family/friends & $135(12)$ & $777(39)$ & $<0.001$ \\
\hline
\end{tabular}

*Frequencies between urban and rural groups were compared by chi-square test.

${ }^{ \pm}$A multiple options question, participants can select more than one option.

Significant single factors for AI knowledge scores including gender, age, education level, occupation, and requests for AI information were incorporated as independent variables into a multivariate analysis. The results showed, for urban residents, age, education level, occupation, and requests for AI information were possible influencing factors of AI knowledge. For rural villagers, gender, age, education level, occupation, and requests for $\mathrm{AI}$ information were possible influencing factors of AI knowledge (Table 4).

Overall, the rural group was significantly more concerned $(p<0.001)$ than the urban group about human infection with AI virus, as measured by concern about AI infection of family and friends, fear of visiting public places and catching the virus, and general concern about human infection with the virus. A comparison of attitude scores associated with AI for all interviewed respondents in Shenzhen city and Xiuning county also 
Table 2 Knowledge associated with Al among residents in Shenzhen and rural villagers in Xiuning, China

\begin{tabular}{|c|c|c|c|c|c|c|c|}
\hline \multirow[t]{2}{*}{ Variables } & \multicolumn{3}{|c|}{$\begin{array}{l}\text { Residents in Shenzhen } \\
(\mathrm{n}=1,826), \text { No. }(\%)\end{array}$} & \multicolumn{3}{|c|}{$\begin{array}{l}\text { Villagers in Xiuning } \\
(\mathrm{n}=2,572), \text { No. }(\%)\end{array}$} & \multirow[t]{2}{*}{$\begin{array}{l}P \\
\text { value* }\end{array}$} \\
\hline & Yes & No & Unknown & Yes & No & Unknown & \\
\hline Human $\mathrm{Al}$ is an infectious disease & $1,352(74)$ & $149(8)$ & $325(18)$ & $1,903(74)$ & $52(2)$ & $617(24)$ & $<0.001$ \\
\hline Humans can be infected with Al virus from poultry & $729(40)$ & $362(20)$ & $735(40)$ & $804(31)$ & $301(12)$ & $1,467(57)$ & $<0.001$ \\
\hline Human infection with Al virus can be prevented & $1,432(78)$ & $44(2)$ & $350(19)$ & $1491(58)$ & $41(2)$ & $1,040(40)$ & $<0.001$ \\
\hline $\begin{array}{l}\text { Humans may not fully recover from infection with Al virus after } \\
\text { treatment }\end{array}$ & $80(4)$ & $1,073(59)$ & $673(37)$ & $166(6)$ & $1,102(43)$ & $1,304(51)$ & $<0.001$ \\
\hline $\begin{array}{l}\text { Human infection with Al virus is associated with hygiene of wet } \\
\text { poultry market }\end{array}$ & $1,472(81)$ & $81(4)$ & $273(15)$ & - & - & - & - \\
\hline Al is not the same as fowl plague (Newcastle disease) & - & - & - & $822(32)$ & $852(33)$ & $898(35)$ & - \\
\hline Knowledgeable about human Al infection & $1,259(69)$ & $567(31)$ & $0(0)$ & $1,453(56)$ & $1,119(44)$ & $0(0)$ & $<0.001$ \\
\hline
\end{tabular}

* Frequencies between urban and rural group were compared by chi-square test.

${ }^{\dagger}$ Scores on these questions are described in Materials and Methods.

Table 3 Knowledge scores associated with Al among urban residents in Shenzhen and rural villagers in Xiuning, China

\begin{tabular}{cccccc}
\hline Area & Median & Range & Inter Quartile Range (IQR) & $\mathbf{Z}^{*}$ & -12.547 \\
\hline Shenzhen $(\mathrm{N}=1,826)$ & 6 & $0-8$ & $4-7$ & $<0.001$ \\
Xiuning $(\mathrm{N}=2,572)$ & 5 & $0-8$ & $3-6$ & \\
\hline
\end{tabular}

*. The $Z$ statistic was obtained from the Wilcoxon rank-sum test for two independent samples.

found that rural villagers were more concerned than urban residents $(p<0.001)$ (Table 5).

Significant single factors for AI attitude scores including gender, age, education level, occupation, requests for AI information, and knowledge scores were incorporated as independent variables into a multivariate analysis. The result showed that, for urban residents, gender, age, education level, occupation, requests for AI information, and knowledge scores were possible influencing factors of AI concern. For rural villagers, gender, education level, requests for AI information, and knowledge scores were possible influencing factors of AI concern (Table 6).

Among the practices used to prevent human AI transmission, 1,152 (64\%) of urban participants used soap for hand washing vs. 965 (38\%) among the rural group $(p<$ 0.001 ). Other practices (use of detergent for dish washing, anti-bacterial solutions, washing powder and shampoo) were similarly, but rarely, adopted by the two groups $(7 \%$ to $<1 \%)$. Regarding eating habits, $45 \%$ (714/ 1,601 ) of Shenzhen participants reported eating less poultry since becoming aware of this infectious disease, whereas $33 \%(732 / 2,213)$ of participants in the Xiuning group reported eating less poultry $(p<0.001)$.

The majority of urban residents $(1,693,93 \%)$ never had direct contact with poultry or their cages when purchasing them. A significant majority of those who had contact with either poultry or cages never subsequently touched their mouth, nose, or eyes $(92 / 112,82 \%)$. Similarly, most rural residents stated they infrequently had direct contact with sick or dead poultry $(2,409,95 \%)$.
The majority of those who had direct contact with sick or dead poultry washed their hands after contact (119/ 133, 89\%).

\section{Discussion}

Despite certain limitations in the study methodology, mainly due to the need to produce simple questions understandable to all groups, our study revealed a number of important differences between KAPs of urban and rural populations for AI. Multivariate analysis demonstrated that age and level of education were likely the main factors giving rise to these differences. The study showed a high degree of awareness of human AI in both urban and rural regions. Awareness evaluations in Thailand [12] and Cambodia [13] after their 20042005 AI outbreaks gave similarly high percentages.

Television was found to be the most effective way to disseminate information on AI in both groups, followed by newspapers in the urban group and family/friends in the rural community. A significant percentage of both groups requested additional information; television, again, being the preferred source. These results confirm findings in Thailand where television proved to be the most efficient source of information [12].

The percentage of participants with 'knowledge associated with human AI' was low, especially in the rural areas where education levels were lower. Olsen et al [12] also found very low percentages of basic knowledge of human AI in rural Thailand before public education campaigns. However, in Italy, Abbate et al [11] found $64 \%$ of 284 poultry workers correctly defined AI as a 
Table 4 Multivariate analysis for possible influencing factors of knowledge scores among urban residents in Shenzhen and rural villagers in Xiuning, China

\begin{tabular}{lllll}
\hline Residents in Shenzhen $(\mathbf{N}=\mathbf{1 , 8 2 6})$ & & & \\
\hline Factors & Coefficients & $\begin{array}{l}\text { Std. } \\
\text { Error* }\end{array}$ & $\mathbf{t}$ & $\begin{array}{l}\boldsymbol{P} \\
\text { value }^{\dagger}\end{array}$ \\
\hline Constant & 3.786 & 0.230 & 16.446 & $<0.001$ \\
Age group & & & & \\
$5-18^{\#}$ & - & - & - & - \\
$19-39$ & 0.211 & 0.113 & 1.860 & 0.063 \\
$40-59$ & -0.007 & & -0.002 & 0.331 \\
$\geq 60$ & 0.015 & & 0.013 & 0.590
\end{tabular}

Highest level of

education

None or

kindergarten"

Primary school

1.529

0.251

Junior high school

1.945

0.232

High school

0.242

College or higher

2.499

0.252

2.828

6.597

$8.027-<0.001$

Occupation

Employed $^{\#}$

Unemployed

Student

$-0.025$

Homemaker

0.500

Retired

0.021

0.732

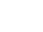

9.919

$<0.001$

Requiring further information on avian influenza Yes $^{\#}$

No

Don't care

$$
-0.446
$$

$-1.979$

0.166

0.114

\begin{tabular}{lcccc}
\hline Villagers in Xiuning $(\mathrm{N}=2,572)$ & & & \\
\hline Constant & 5.003 & 0.172 & 29.150 & $<0.001$ \\
Females & -0.394 & 0.077 & -5.143 & $<0.001$
\end{tabular}

Age group

$5-18^{\#}$

19-39

40-59

0.021

$\geq 60$

$-0.029$

$$
-0.796
$$

Highest level of education

None or

kindergarten"

Primary school $\quad 0.479$

Junior high school $\quad 1.067$

High school

College or higher

1.298

1.422

Occupation

Employed"

Unemployed

Students

Homemakers

$-0.012$

0.430

Retired

$-0.012$

$-0.016$

$\begin{array}{lll}- & - & - \\ & 0.025 & 0.771 \\ & -0.030 & 0.599 \\ 0.099 & -8.054 & <0.001\end{array}$

0.105

0.120

0.182

0.460

4.570

8.895

$<0.001$

$7.121-<0.001$

$3.093 \quad 0.002$
Table 4: Multivariate analysis for possible influencing factors of knowledge scores among urban residents in Shenzhen and rural villagers in Xiuning, China (Continued)

Requiring further information of avian influenza

Yes $^{\#}$

$\begin{array}{lllll}\text { No } & -0.593 & 0.271 & -2.191 & 0.029\end{array}$

Don't care

$-2.819$

0.098

$-28.700<0.001$

\# Reference group.

* Std Errors for the non-significant items were not available by using SPSS software.

${ }^{\dagger}$ Obtained by multiple linear regression model.

Table 5 Attitude scores associated with Al among urban residents in Shenzhen and rural villagers in Xiuning,

China

\begin{tabular}{cccccc}
\hline Area & Median & Range & IQR & $\mathbf{Z}^{*}$ & $\boldsymbol{P}$ value \\
\hline Shenzhen $(\mathrm{N}=1,826)$ & 3 & $0-6$ & $0-5$ & -13.862 & $<0.001$ \\
Xiuning $(\mathrm{N}=2,572)$ & 3 & $0-6$ & $2-6$ & & \\
\hline
\end{tabular}

*. The $\mathrm{Z}$ statistic was obtained from the Wilcoxon rank-sum test for two independent samples.

contagious infection caused by a virus that can affect all species of birds. Nearly all workers identified poultry and wild birds as common vectors. These percentages are much higher than our results here. A recently published Italian study showed that knowledge of AI was greater among more highly educated populations, with a similar percentage aware that AI was preventable [14].

The urban group in this survey was less concerned about human infection with AI than their rural counterparts, probably due to their greater awareness of $\mathrm{AI}$, in part, resulting from their higher level of education. In the Hong Kong SAR, with its high level of education, a telephone survey found $36 \%$ of respondents agreed that buying live chickens was a health risk and only $9 \%$ estimated a $>50 \%$ likelihood of resultant sickness [9]. In addition, a telephone survey conducted in Hong Kong SAR in 2005 [15], which evaluated perceptions related to human AI and its association with anticipated psychological and behavioral responses in an outbreak, revealed that only $19.9 \%$ of participants avoiding visiting hospitals due to fear of AI, and a general education level (42.4\% was matriculated or above) higher than in our study population.

Multivariate analysis results suggested, for both populations in our study, a possible relationship between AI knowledge, some of the demographic characteristics, and requests for AI information existed, as well as a possible relationship between AI attitude, some of the demographic characteristics, knowledge scores, and requests for AI information. However, a quantitative 
Table 6 Multivariable analysis for possible influencing factors of attitude scores among urban residents in Shenzhen and rural villagers in Xiuning, China

\begin{tabular}{|c|c|c|c|c|}
\hline \multicolumn{5}{|c|}{ Residents in Shenzhen $(\mathrm{N}=1,826)$} \\
\hline Risk factors & Coefficients & $\begin{array}{l}\text { Std. } \\
\text { Error* }\end{array}$ & $\mathbf{t}$ & $\begin{array}{l}P \\
\text { value }^{\dagger}\end{array}$ \\
\hline Constant & 2.224 & 0.216 & 10.275 & $<0.001$ \\
\hline Female & 0.263 & 0.099 & 2.658 & 0.008 \\
\hline \multicolumn{5}{|l|}{ Age group } \\
\hline $5-18^{\#}$ & - & - & - & - \\
\hline $19-39$ & -0.011 & & -0.011 & 0.934 \\
\hline $40-59$ & 0.017 & & 0.016 & 0.831 \\
\hline$\geq 60$ & -0.517 & 0.223 & -2.319 & 0.020 \\
\hline \multicolumn{5}{|l|}{$\begin{array}{l}\text { Highest level of } \\
\text { education }\end{array}$} \\
\hline $\begin{array}{l}\text { None or } \\
\text { kindergarten }\end{array}$ & - & - & - & - \\
\hline Primary school & 0.479 & 0.155 & 3.087 & 0.002 \\
\hline Junior high school & 0.022 & & 0.010 & 0.178 \\
\hline High school & -0.281 & 0.122 & -2.298 & 0.022 \\
\hline College or higher & -0.655 & 0.145 & -4.531 & $<0.001$ \\
\hline \multicolumn{5}{|l|}{ Occupation } \\
\hline Employed ${ }^{\#}$ & - & - & - & - \\
\hline Unemployed & 0 & & 0 & 0.988 \\
\hline Student & -0.552 & 0.243 & -2.273 & 0.023 \\
\hline Homemaker & -0.031 & & -0.030 & 0.840 \\
\hline Retired & -0.017 & & -0.014 & 0.606 \\
\hline \multicolumn{5}{|c|}{ Requiring further information of avian influenza } \\
\hline Yes $^{\#}$ & - & - & - & - \\
\hline No & -0.961 & 0.167 & -5.753 & $<0.001$ \\
\hline Don't care & -0.815 & 0.123 & -6.634 & $<0.001$ \\
\hline Knowledge score & 0.144 & 0.023 & 6.194 & $<0.001$ \\
\hline \multicolumn{5}{|c|}{ Villagers in Xiuning $(\mathrm{N}=2,572)$} \\
\hline Constant & 3.092 & 0.170 & 18.148 & $<0.001$ \\
\hline Females & 0.286 & 0.078 & 3.667 & $<0.001$ \\
\hline \multicolumn{5}{|c|}{ Highest level of education } \\
\hline $\begin{array}{l}\text { None or } \\
\text { kindergarten }\end{array}$ & - & - & - & - \\
\hline Primary school & 0.014 & & 0.015 & 0.987 \\
\hline Junior high school & -0.021 & & -0.022 & 0.895 \\
\hline High school & -0.022 & & -0.023 & 0.957 \\
\hline College or higher & -0.864 & 0.473 & -1.826 & 0.068 \\
\hline \multicolumn{5}{|c|}{ Requiring further information of avian influenza } \\
\hline Yes $^{\#}$ & - & - & - & - \\
\hline No & -1.563 & 0.287 & -5.445 & $<0.001$ \\
\hline Don't care & -1.282 & 0.117 & -10.992 & $<0.001$ \\
\hline Knowledge score & 0.140 & 0.020 & 7.014 & $<0.001$ \\
\hline
\end{tabular}

\# Reference group.

* Std Errors for the non-significant items were not available by using SPSS software.

${ }^{+}$Obtained by multiple linear regression model. relationship cannot be evaluated from the data in our present study, and such an issue could be explored by further investigations in the future.

Our study showed a higher level of proper hygienic practice among urban residents. A study by Olsen et al. in Thailand before the 2004 outbreak demonstrated similar results among rural residents [12]. Another study conducted in Italy among the general population showed low compliance with precautionary behavior [14]. All implied the practice of precautionary activities in avoiding infection by AI virus needs to be strengthened.

Both groups in the present study reported a higher proportion of eating habit changes after awareness of the spread of AI, especially the rural villagers, who had more concern about AI, comparison with a survey conducted by Lau et al [15]. Facing AI, a new, emerging infectious disease with a high fatality rate, it is expected that people will have varying degrees of concern, ranging from indifference to panic. Timely and comprehensive public-risk communications from the government or other professional agencies are necessary to appease the possible negative social psychological influences such an outbreak would bring, in addition to the importance of persuading the public to take appropriate attitudes towards their practices of disease control and prevention.

Despite the novelty and significance of these findings, one methodological consideration that ought to be highlighted when interpreting these results is that the scores of AI knowledge and attitudes were not validated in China.

\section{Conclusions}

Studies conducted in China, Thailand and Vietnam revealed that risk factors for $\mathrm{H} 5 \mathrm{~N} 1$ infection included recent exposure to live poultry, direct contact with dead poultry that had died of unknown causes [8], and the presence in the household of dead or sick poultry $[3-6,9,10,13]$. This study investigated the levels of knowledge, attitude and practices regarding these risk factors and could provide scientific support to assist the Chinese government in developing strategies and health education campaigns to prevent transmission of the AI virus among the general population. These campaigns should include such advice as avoidance of direct contact with sick or dead poultry, and use of protective equipment such as gloves and masks when contact is unavoidable. Such campaigns should utilize television as the primary medium of dissemination in all localities, 
with newspapers and the internet being the secondary source in urban areas, and local opinion leaders, such as family/friends and local doctors, taking a significant role in rural areas.

Additional file 1: Questionnaire S1 Questionnaire S1 Questionnaire of population based assessment of avian exposure and knowledge, attitudes and practices (KAPs) associated with avian influenza in Shenzhen. This structured questionnaire had been used in our study to collect information about knowledge, attitudes and practices (KAPs) associated with avian influenza in Shenzhen.

Click here for file

[http://www.biomedcentral.com/content/supplementary/1471-2334-1034-S1.PDF ]

Additional file 2: Questionnaire S2 Questionnaire of population based assessment of avian exposure and knowledge, attitudes and practices (KAPs) associated with avian influenza in Xiuning. This structured questionnaire had been used in our study to collect information about knowledge, attitudes and practices (KAPS) associated with avian influenza in Xiuning.

Click here for file

[http://www.biomedcentral.com/content/supplementary/1471-2334-1034-S2.PDF ]

\section{Acknowledgements}

We thank the Health Bureaus of Shenzhen, Huang Shan and Xiuning for their assistance in coordinating the field investigations and provision of logistical support. This study was supported by grants from the China-U.S. Collaborative Program on Emerging and Re-emerging Infectious Diseases, and from the Ministry of Science and Technology of the People's Republic of China (2004BA519A17, 2004BA519A71 and 2006BAD06A02). The views expressed in this study are those of the authors and do not represent the policy of the Chinese Center for Disease Control and Prevention.

\section{Author details}

${ }^{1}$ Office for Disease Control and Emergency Response, Chinese Center for Disease Control and Prevention, Beijing, China. ${ }^{2}$ Chinese Field Epidemiology Training Program, Chinese Center for Disease Control and Prevention, Beijing, China. ${ }^{3}$ Anhui Provincial Center for Disease Control and Prevention, Hefei, China. ${ }^{4}$ Shenzhen Center for Disease Control and Prevention, Shenzhen, China. ${ }^{5}$ Chongqing Medical University, Chongqing, China. ${ }^{6}$ Huanshan Center for Disease Control and Prevention, Huangshan, China. ${ }^{7}$ Xiuning Center for Disease Control and Prevention, Xiuning, China. ${ }^{8}$ Influenza Division, National Center for Immunization and Respiratory Diseases, Center for Disease Control and Prevention, Atlanta, USA.

\section{Authors' contributions}

HY contributed to study design; NX, YS, JW, and SZ participated in the field investigations, collected data from participants for the study, and helped to analyze the data; HY drafted the manuscript; JM helped to revise the manuscript. All other co-authors participated in collection and management of data. All authors read and approved the final manuscript.

\section{Competing interests}

The authors declare that they have no competing interests.

Received: 24 July 2009

Accepted: 21 February 2010 Published: 21 February 2010

\section{References}

1. World Health Organization: Cumulative number of confirmed human cases of avian influenza A/(H5N1) reported to WHO. 2009http://www. who.int/crr/disease/avian_influenza/country/cases_table_2009_07_01/en/ index.html, Accessed July 3.

2. Writing Committee of the Second World Health Organization: Consultation on Clinical Aspects of Human Infection with Avian Influenza A (H5N1) virus. Update on Avian Influenza A (H5N1) Virus Infection in Humans. N Engl J Med 2008, 358:261-273.

3. Mounts AW, Kwong H, lzurieta HS, Ho Y-y, Au TK, Lee M, Bridges CB, Williams SW, Mark KH, Katz JM, Thompson WW, Cox NJ, Fukuda K: Casecontrol study of risk factors for avian influenza A ( $\mathrm{H} 5 \mathrm{~N} 1)$ disease, Hong Kong, 1997. J Infect Dis 1999, 80:505-508.

4. Areechokchai D, Jiraphongsa C, Laosiritaworn Y, Hanshaoworakul W, O'Reilly M: Investigation of avian influenza (H5N1) outbreak in humans Thailand, 2004. Morb Mortal Wkly Rep 2006, 55:S3-S6.

5. Dinh PN, Long HT, Tien NTK, Hien NT, Mai LTQ, Phong LH, Tuan LV, Tan HV, Nguyen NB, Tu PV, Phuong NTM, WHO/Global Outbreak Alert and Response Network Avian Influenza Investigation Team in Vietnam: Risk factors for human infection with avian influenza A H5N1, Vietnam, 2004. Emerg Infect Dis 2006, 12:1841-1847.

6. Zhou L, Liao Q, Dong L, Huai Y, Bai T, Xiang NJ, Shu YL, Liu W, Wang SW, Qin PZ, Wang M, LV J, Chen RY, Feng ZJ, Yang WZ, Uyeki TM, Yu Hongjie: Risk factors for human illness with avian influenza A (H5N1) virus infection in China, 2005-2007. J Infect Dis 2009, 199:1726-1734.

7. Yu HG, Shu YL, Hu SX, Zhang H, Gao ZC, Chen HL, Dong J, Xu CL, Zhang Y, Xiang NJ, Wang M, Guo YJ, Cox NJ, Lim W, Wang Y, Yang WZ: The first confirmed human case of avian influenza A (H5N1) in mainland China. Lancet 2006, 367-84.

8. Yu HG, Feng ZJ, Zhang XF, Xiang NJ, Huai Y, Zhou L, Li ZJ, Xu CL, Luo HM, He JF, Guan XH, Yuan ZA, Li YT, Xu LS, Hong RT, Liu XC, Zhou XY, Yin WW, Zhang SX, Shu YL, Wang MW, Wang Y, Lee CK, Uyeki TM, Yang WZ, the Avian Influenza H5N1 Study Group: Human influenza A (H5N1) cases, urban areas of People's Republic of China, 2005-2006. Emerg Infect Dis 2007, 13:1061-1064.

9. Fielding R, Lam WWT, Ho EYY, Lam TH, Hedley AJ, Leung GM: Avian influenza risk perception, Hong Kong. Emerg Infect Dis 2005, 11:677-682.

10. Fielding R, Bich TH, Quang LN, Lam WWT, Leung GM, Tien TQ, Ho EYY, Anh LV: Live poultry exposures, Hong Kong and Hanoi, 2006. Emerg Infect Dis 2007, 13:1065-1067.

11. Abbate R, Di Giuseppe G, Marinelli P, Angelillo IF: Knowledge, attitudes and practices of avian influenza, poultry workers, Italy. Emerg Infect Dis 2006, 12:1762-1765.

12. Olsen SJ, Laosiritaworn Y, Pattanasin S, Prapasiri P, Dowell SF: Poultryhandling practices during avian influenza outbreak, Thailand. Emerg Infect Dis 2005, 11:1601-1603.

13. Ly S, Van Kerkhove MD, Holl D, Froehlich Y, Vong S: Interaction between humans and poultry, rural Cambodia. Emerg Infect Dis 2007, 13:130-132.

14. Di Giuseppe G, Abbate R, Albano L, Marinelli P, Angelillo IF: A survey of knowledge, attitudes and practices towards avian influenza in an adult population of Italy. BMC Infect Dis 2008, 8:36-44.

15. Lau JTS, Kim JH, Tsui H, Griffiths S: Perceptions related to human avian influenza and their associations with anticipated psychological and behavioral responses at the onset of outbreak in the Hong Kong Chinese general population. Am J Infect Control 2007, 35:38-49.

Pre-publication history

The pre-publication history for this paper can be accessed here:http://www biomedcentral.com/1471-2334/10/34/prepub

doi:10.1186/1471-2334-10-34

Cite this article as: Xiang et al: Knowledge, attitudes and practices (KAP)

relating to avian influenza in urban

and rural areas of China. BMC Infectious Diseases 2010 10:34. 